\title{
SCID Mouse
}

National Cancer Institute

\section{Source}

National Cancer Institute. SCID Mouse. NCI Thesaurus. Code C14294.

Severe combined immunodeficient (SCID) mice like their human counterparts with immunodeficiency diseases are helpless not only to fight infection but also to reject transplanted tissue. These animals lack both T and B-cells and are used extensively in researches of immune disease or tissue transplantation. 